\title{
OFICINA DE ARQUEOLOGIA EM PÁTIO DE ESCOLA NA REDUÇÃO DE SANTO ÂNGELO CUSTÓDIO
}

\author{
Cláudio Baptista Carle ${ }^{1}$
}

\section{RESUMO}

Texto referente a trabalho educativo sobre arqueologia, realizado com estudantes da escola básica e ensino superior em pátio de escola estadual em Santo Ângelo. Aula prática de defesa do patrimônio arqueológico.

Palavras-chave: Santo Ângelo; arqueologia; educação.

\begin{abstract}
Text for the archeology of educational work, conducted with students from elementary school and higher education in the courtyard of the State School in San Angelo. Classroom practice of archaeological heritage protection.
\end{abstract}

Keyworks: Santo Ângelo; archeology; students.

\footnotetext{
${ }^{1}$ Laboratório de Estudos sobre Cultura Material, Programa de Pós-Graduação em Antropologia, Instituto de Ciências Humanas, Universidade Federal de Pelotas. E-mail: cbcarle@yahoo.com.br.
} 


\section{INTRODUÇÃO}

A oficina em Santo Ângelo é parte final de um estudo realizado, o final de uma pesquisa da área de pátios de residências, tendo sido realizada em escola estadual de ensino fundamental e médio, com estudantes de nível superior e com pessoas da comunidade santoangelense. Esta ação foi autorizada pela diretora da escola e serviu de Oficina de Arqueologia no encontro Sobre Missões Jesuíticas da Universidade Regional Integrada (URI) - Santo Ângelo. O trabalho teve autorização verbal também da Superintendente Regional do IPHAN, tendo em vista a discussão que se travava até aquele momento sobre o sítio arqueológico de Santo Ângelo Custódio e sua forma de preservação. Santo Ângelo Custódio é um sítio que envolve toda a área central da atual cidade de Santo Ângelo e as partes do sítio estão em áreas muradas, que a Lei 3.924/61 não protege. A situação da escola estadual é a mesma.

O trabalho proporcionou além da interação com a comunidade escolar a realização de uma investigação em forma de oficina de arqueologia, no pátio da escola, que fica a frente da Praça da Catedral Angelopolitana, área que, em conjunto com os pátios das residências da área central da cidade, estão sendo assoladas por inserção de estruturas permanentes. A área da escola permitiu o trabalho de investigação e a preservação dos remanescentes ainda existentes do Antigo Povoado de Santo Ângelo Custódio. A preservação em nosso entendimento depende do conhecimento do que são estes e esta só pode existir se for trabalhada de forma prática pela população. O nosso trabalho poderia ser enquadrado nas propostas da Educação Patrimonial, como sugere o IPHAN, mas não considero este trabalho educação, pois nele carece de no mínimo dois pontos principais do processo ensinoaprendizagem que é a retro-alimentação e a avaliação. Sei que outros pesquisadores fazem trabalhos similares e os indicam como Educação Patrimonial, mas este não o é.

Esta descrição foi encaminhada ao IPHAN e a Comissão de Patrimônio Arqueológico do Município de Santo Ângelo. O trabalho aconteceu com equipe de estudantes de diversos cursos da URI - Santo Ângelo, estagiário do Núcleo de Arqueologia - CCM - URI - Santo Ângelo, bolsista NArq-UNICRUZ, aluna de pós-graduação em História (área de Arqueologia) da PUCRS, e representantes da comunidade de Santo Ângelo, no dia onze (11) do mês de setembro de 2004.

\section{METODOLOGIA}

O trabalho foi auto financiado e a partir de disponibilidade de alguns valores pela URI-Santo Ângelo. Pretendia-se que fosse financiado a partir das verbas destinadas pelas 
instituições em cooperação (URI-UNICRUZ-PUCRS) e pelos proprietários dos terrenos (neste caso o governo estadual) que pretendessem desenvolver intervenções no solo do antigo povoado missioneiro. O problema estava exatamente em não haver um reconhecimento desta área como sendo sítio arqueológico. O trabalho ajudou a propor tal preservação.

A área que sofreu o processo de aprendizagem, estudo e intervenção está localizada na parte central da cidade de Santo Ângelo, em um retângulo correspondente à Av. Rio Grande do Sul (Sul), Rua Marechal Floriano (Leste), Rua Sete de Setembro (Norte) e Rua Quinze de Novembro (Oeste), tendo como referência mais central a praça atual da cidade à frente da Catedral de Santo Ângelo, sendo o sítio arqueológico cadastrado no IPHAN, com área de aproximadamente $730.800 \mathrm{~m}^{2}$. E o ponto específico corresponde ao pátio da escola estadual (nome não revelado por questões éticas) que está à frente da igreja e é parte da área correspondente às antigas casas dos índios.

Apresento os três momentos de ação, sendo que destaco o procedimento realizado em campo de cunho acadêmico, pois em se tratando de sítio arqueológico isto deve estar explicitado, pois somos, nós os arqueólogos, fiscalizados pelo IPHAN. O processo de aproximação com a comunidade foi realizada pela equipe responsável pelo museu municipal de Santo Ângelo e pela URI. Após encontrar os interessados eu realizei uma explanação histórica sobre o povoado, sobre autores científicos que tratam do tema (explicitado no item discussão), o que nos possibilitaria uma descrição densa (GEERTZ, 1978), e depois passamos a discutir com os participantes as motivações pessoais sobre a questão do patrimônio arqueológico de Santo Ângelo. Após esta introdução realizamos o trabalho de campo efetivamente.

O trabalho em campo seguiu a proposta de multi-estágios desenvolvida por Redman (1973), de Unidade Sociológica desenvolvida por Funari (1988) associadas para o reconhecimento das ocupações antigas na área, relacionando as ocupações circunvizinhas do antigo povoado de Santo Ângelo Custódio. Realizamos então a identificação altimétrica e locacional da área e ser escavada valendo-nos do uso de luneta topográfica.

O local de escavação foi determinado após amplo reconhecimento da área (pátio da escola) e do entorno a ser pesquisado, identificando uma base de coluna que serviu de ponto de indicação principal a sofrer a intervenção. A escola foi escolhida por ainda possuir um amplo espaço com presença de solo não pavimentado, o que possibilitava uma visualização de possíveis indícios do sítio que se encontra sob o solo atual.

A continuidade do modelo Redman (1973) / Funari (1988) se deu pelo levantamento intensivo na ampla área do pátio em busca de áreas de atividade, tais como: fundações, 
fogões, silos, concentrações cerâmicas (potes fragmentados ou telhas). Realizamos coletas superficiais sistemáticas em dois pontos com concentração de material e um destes foi selecionado para escavação. Realizamos tradagens diagnósticas da diacronia do terreno, marcamos área de trincheiras e quadrículas de escavação.

O trabalho se desenvolveu inicialmente no primeiro momento sem uma intervenção direta no sítio e sem retirada de artefatos do local. A partir disso é que realizamos as coletas e os locais passíveis de escavações foram trabalhados conforme plano específico de intervenção que elaboramos com os educandos e comunidade envolvidos na aprendizagem. A escolha da área foi determinada em virtude de sua possibilidade de destruição e por estar afastado da área de uso pelos estudantes da escola em seus recreios, o que poderia causar um risco às crianças da escola.

Durante a realização de levantamento realizamos linhas de caminhamento sistemático, que cobriram todo o pátio da escola. As linhas de caminhamento foram orientadas em sentido norte-sul. Sobre estas linhas foram realizados os levantamentos de estruturas e a identificação das mesmas em croquis esquemáticos da área.

A partir da realização do levantamento foram definidas as áreas de configuração das Unidades Sociológicas. Neste caso a presença de cerâmica (principalmente telhas) e de duas grandes pedras, uma claramente uma base de coluna em arenito. A área com as pedras foi escolhida para intervenção sub-superfície por estar distante do local de maior movimentação. Os estudantes aprenderam que ao serem determinadas as Unidades Sociológicas e suas possíveis sucessões cronológicas na área, estas permitem as futuras atitudes de valorização (tais como salvamentos, demarcações para proteção, etc.) destes e dos novos locais do sítio reconhecidos. As Unidades Sociológicas referem-se ao cotidiano sincrônico das deposições arqueológicas reconhecidas sobre o solo, ou em estratos, atualmente subterrâneos, de ocupações passadas, dispostas de forma harmônica (FUNARI, 1988). Pretendíamos não privilegiar uma Unidade sobre outra, ou sua destruição e sucessão por outra, mas sua continuidade e inter-relação com outras Unidades anteriores e posteriores. O que ocorreu em função do tempo de ação foi o dar maior valor as Unidades do período missioneiro. Às Unidades identificadas procedemos como o método de escavação de Redman (1973), conjugado com as seções cumulativas de Funari (1988).

Terminado o trabalho de campo realizamos uma reunião conjugando todos os artefatos encontrados dos móveis (fragmentos de várias matérias-primas) como também as estruturas de fundação, piso de chão batido, acúmulos de telhas correspondendo a antigo telhado de casa de índio, e discutimos os possíveis usos destes espaços e materiais reconhecidos. A partir do 
descarte das áreas as formas de revitalização e assim valorização de vestígios que muitas vezes são pouco aparentes. Ao final definimos o que seria feito com os objetos retirados do local. Neste sentido a questão da musealização apareceu novamente de maneira forte, mas as ideias, mesmo minhas, não ultrapassaram o que já está estabelecido sobre a ideia de museu o mais bonito deve ser exposto e o comum armazenado em reservas técnicas.

\section{DISCUSSÃo}

A argumentação inicial que segue está baseada em autores que discutem amplamente a questão de missões e assim cabe dizer que de início focaremos apresentando as discussões historiográficas sobre o tema Missões, o próprio processo histórico de Santo Ângelo Custódio em um discorrer diacrônico desenvolvido pela professora Clarissa S. Rahmeier e por mim (2004) e depois a questão própria deste trabalho.

Os estudos das missões podem ser visualizados em diversos autores que fundamentam as ações sobre os sítios, cabia então a nós, em uma prévia ação junto a Santo Ângelo Custódio, realizar um panorama do que se produzira sobre as Missões até aquele momento. A forma de abordagem histórica destes autores possibilitam aos novos interlocutores do patrimônio entender os sistemas de valorização realizados pela história para com estes povoados. Assim, damos sequência às discussões sobre os autores travada com os interessados no trabalho. Iniciamos por Antonio Sepp (1972), um dos autores mais lidos sobre o tema Missões no Brasil, pois é um padre que viveu aquela época. Ele descreve como chegou a São Miguel, como dividiu a população do povoado, como criou uma nova redução (São João Batista) e como com estes índios desenvolveu indústrias cerâmicas e de ferro.

No contexto de aproximação com o entendimento pós-missioneiro, mas de certa forma ligado ao próprio processo, discutimos Felix Azara (1943), que em momento posterior à dispersão dos índios Guarani por ampla área visita as várias cidades criadas por eles e constrói o texto que descreve a história desta saga indígena no sul da América do Sul. O economista Oreste Popescu (1967) discute a forma de implementação dos modelos de produção europeia entre as sociedades que Kern (1982) identifica como neolíticas. Estes guaranis desenvolveram um sistema sob, pelo menos na ideia do autor, a coordenação dos jesuítas. Um sistema produtivo próprio e eficiente para os parâmetros da época, uma percepção cara da intenção do modelo capitalista dos padres na sua "missão" na América.

No âmbito de uma produção mais acadêmica Arno Kern (1982), natural de Santo Ângelo, dedica sua vida aos estudos históricos, mas principalmente arqueológicos das Missões, sendo que sua obra é incontável, tendo a "Utopia Política" voltado os olhos de 
muitos outros pesquisadores para o tema. Em 1991 desenvolve uma das mais amplas, em termos de países envolvidos, escola de campo em arqueologia (1993). A escola missioneira apresenta uma lista com mais de 20 arqueólogos que tiveram formação básica ou ampliada nos diversos trabalhos de campo desenvolvidos por este pesquisador.

As sínteses se sucedem a este estudo de Kern (1982) e percebemos Moacyr Flores (1986, 1988), um dos "velhos ratos de arquivo", como costumávamos chamar no período em que fazia a graduação, produziu duas sínteses que se deve prestar atenção ao tratar à questão missioneira a proposta política que envolvia o processo de formação dos espaços reducionais. O padre jesuíta Arnaldo Bruxel (1987) busca sintetizar para uma linguagem menos acadêmica a história dos trinta povos Guarani e com isso possibilita a estudantes e comunidade menos acostumada aos linguajares acadêmicos compreender este universo histórico. Ramon Gutierrez (1987) possibilita a ampliação do conhecimento trabalhado por autores anteriores sobre os Trinta Povos Guaranis com uma produção bilíngüe que marca a aproximação entre pesquisadores dos quatro países (Brasil, Uruguay, Paraguay e Argentina) envolvidos no processo histórico de referência. O francês Maxime Haubert (1990), preocupado em evidenciar mais os seres humanos que suas realizações, desenvolve um texto dando enlevo aos grupos humanos em aproximação e distanciamento nesta história.

Após esta discussão mais ampla sobre as sínteses, nos dedicamos a estudos mais específicos dos possíveis achados que poderiam ser encontrados na campanha no espaço da escola. Analisamos o artigo que estuda os metais (CARLE, 1991), que visualiza como os Jesuítas tiveram força de aproximação dos caciques para então arregimentar aldeias inteiras para suas missões e com isso formando um elo que segundo Metraux não mais se quebraria nas culturas ameríndias, o elo criado pela busca incessante do metal para os mais diversos usos. Os estudos da cerâmica doméstica (potes de uso cotidiano) realizados por Alyne Escobar e Paulo Fraga (1991), fortemente calcado em estudos anteriores, que são sínteses amplas sobre a confecção e uso destes objetos, são aportes importantes para identificar a presença indígena e seu processo de inserção de modelos culturais europeus, mas com forte resistência étnica. José Otávio C. de Souza (1991) também hoje é um os maiores conhecedores do universo missioneiro, mas neste texto específico demonstra de forma simples o processo de reconhecimento arqueológico de um dos povoados missioneiros. Hoje mais dedicado à Antropologia dos Guarani, tem como ampla área de trabalho etnográfico a região dos Sete Povos.

Avaliado este aporte científico produzido re-visitamos a história do povoado que se fazia foco de nosso trabalho patrimonial. Percebemos que o antigo povoado de Santo Ângelo 
Custódio ainda demonstra sua grandiosidade através de um acervo arqueológico que, além do arquivo solo, constituem o conjunto de cultura material os inúmeros remanescentes arquitetônicos, objetos e utensílios demonstrativos do cotidiano da redução e das ocupações posteriores. É importante salientar que a redução de Santo Ângelo Custódio foi criada em 1707, última dos povoados Guarani na expansão para leste, instalada na região sudeste do Rio Ijuí, em local que se mostrou pouco afeito ao estabelecimento do povoado, deslocado então para área ultrapassando o rio Ijuí, contrariando as intenções iniciais dos jesuítas, conforme a historiografia, pois ficaria menos protegido das ações do inimigo, não tendo o grande Ijuí como limite físico a ações militares dos portugueses, no atual Rio Grande do Sul. A região era então atribuída ao império espanhol pelo Tratado de Tordesilhas.

Com São João Batista, São Luiz Gonzaga, São Nicolau, São Francisco de Borja, São Lourenço Mártir e São Miguel, Santo Ângelo Custódio integrava, no século 18, a região conhecida como Sete Povos Orientais do Uruguai. Em 1750, o Tratado de Madri atribuiu ao império português o território dos Sete Povos, mas a população guarani recusou-se a abandoná-lo, originando a Guerra Guaranítica. Em 1756 os Sete Povos foram ocupados pelos exércitos espanhol e português, para obrigar ao cumprimento do Tratado de 1750. Em São Miguel, um incêndio destruiu parte da residência dos padres e da igreja. Parte da população abandonou o povoado, dirigindo-se para território hoje argentino, e parte, em 1757, acompanhou o exército português quando este voltou para Rio Pardo.

A Redução, em 1762, juntamente com todo o território dos Sete Povos, foi devolvida aos guaranis e jesuítas, mas, em 1768, os jesuítas foram expulsos. Santo Ângelo e as demais missões passaram a ser administrados por funcionários espanhóis. Em 1801 houve nova ocupação, com incorporação definitiva ao império português e ao território do Brasil. Em 1828, durante a Guerra da Cisplatina, os Sete Povos foram outra vez invadidos, pelo uruguaio Frutuoso Rivera. Houve um saque generalizado e parte da população acompanhou as tropas de Rivera para o Uruguai.

Com a decadência do conjunto das missões a partir do final do século 18 e a reorganização quase total de Santo Ângelo após 1828, foi sendo o povoado modificado progressivamente ao longo de todo o século XIX e início do século $\mathrm{XX}$, provavelmente utilizando a mão de obra indígena ainda residente no local, construindo as edificações com representação neo-clássica, conforme podemos hoje perceber nas paredes do Museu Municipal e a seu lado na edificação da Moto Peurse e como se apresentou neste Sindicato Rural. 
O sítio arqueológico de Santo Ângelo Custódio corresponde a uma área de $730.000 \mathrm{~m}^{2}$ que abrange o núcleo principal do antigo povoado missioneiro, levantado e registrado pelo arqueólogo Cláudio Baptista Carle, em 1992, em conjunto com o Museu Municipal de Santo Ângelo, sob coordenação na época de Gladis Pippi. Esta área está englobada pela malha urbana da cidade de Santo Ângelo. O Sítio Arqueológico de Santo Ângelo Custódio, além de não ter sua integridade garantida pelo registro arqueológico, pois suas partes encontram-se hoje no interior de áreas muradas, não sofre hoje ações de preservação direta e efetiva da prefeitura para sua proteção através da Comissão de Patrimônio Arqueológico Municipal.

O processo de trabalho com inserção da comunidade não pode ser entendido como um estudo de tomada de posição sobre os sítios, mesmo neste caso em que o lugar, Santo Ângelo, nunca deixou de ser ocupado, mesmo antes de sua significação como representação da "saga da conquista espiritual" (GUTIERREZ, 1987). O desenvolvimento das etapas de campo foram seguidas com atenção e interesse pelos protagonistas (da oficina) e por parte ampla de estudantes da escola em investigação. Ao verificarem os contextos, mesmo que muito alterados pelos movimentos antrópicos do solo, inferiram através de diversas falas as situações de destruição em que se encontra o seu patrimônio. Aparentemente todos tinham ciência da necessidade de preservação e estudo do mesmo. Mas desconheciam-no, e questionados pelos artefatos arqueológicos existentes no Museu, disseram em grande maioria que não os entendem como tal.

\section{RESULTADOS}

O estudo propiciou a salvaguarda de bens e possibilitou o conhecimento maior da área que corresponderia à área da casa dos índios da antiga redução. Foi possível constatar que a ocupação da área alterou significativamente o espaço de Santo Ângelo. O trabalho foi realizado em interior de área murada não protegida inicialmente pela lei 3.924/61 (lei da arqueologia) cujo interesse do proprietário em preservar os vestígios ali existentes suscitaram esta ação.

Esta foi a área em que houve acompanhamento e que possibilitou fazer as fundações, sendo que foi alertada ao proprietário a necessidade de preservação das paredes originais e da conservação das pedras que fossem deslocadas devendo ser entregues à prefeitura para a Comissão de Patrimônio Arqueológico. Segundo Reportagem de Zero Hora as paredes estão sendo destruídas. O que deve ter sido acompanhado pela Comissão de Patrimônio.

A percepção sobre o fato dos materiais arqueológicos estarem apenas depositados me fez rever a ideia de difusão possível dos museus, em realidade não há um contexto 
arqueológico exposto, mas materiais que são oriundos de pesquisas arqueológicas expostos junto com outras peças que em sua musealização estão individualizadas e pouco formando contextos, assim o que temos no museu é uma exposição de curiosidades.

A preservação, em nosso entendimento, depende do conhecimento e este só pode existir se for trabalhado. $\mathrm{O}$ nosso trabalho poderia ser enquadrado nas propostas da Educação Patrimonial, como sugere o IPHAN, mas não considero este trabalho educação, pois nele carece um dos pontos principais da educação, que é a retro-alimentação e a avaliação. Sei que outros pesquisadores fazem trabalhos similares e os indicam como Educação Patrimonial, mas este não o é.

\section{AGRADECIMENTOS}

A minha amiga Beatriz dos Santos Landa, pela hospitalidade e pela identificação de meus esforços em realizar trabalhos além do espaço acadêmico.

\section{REFERÊNCIAS}

AZARA, F. Descripcion e historia del paraguay y del Rio de La Plata. Buenos Aires: Ed. Bajel, 1943.

BRUXEL, A. Os trinta povos guaranis. 2 ed. Porto Alegre: Nova Dimensão, 1987.

CARLE, C. B. O Material Metálico de São Lourenço Mártir e São João Batista, RS Possibilidades de Conformação e Uso. In: Anais do IX Simpósio Nacional de estudos missioneiros - as missões depois das missões. 8 a 10 de out. de 1991, UNIIJUÍ-Campus Sta. Rosa, Santa Rosa. 1991.

ESCOBAR, A. S.; FRAGA, P. R. P. Análise Interpretativa da Cerâmica Doméstica do Sítio Missioneiro de São João Batista, RS: Primeiras Notícias. In: Anais do IX Simpósio Nacional de estudos missioneiros - as missões depois das missões. 8 a 10 de outubro 1991 - UNIJUÍ - Câmpus Santa Rosa, Santa Rosa. 1991.

FLORES, M. Colonialismo e missões jesuíticas. 2. ed. Porto Alegre: Nova Dimensão, 1986.

FLORES, M. História do Rio Grande do Sul. 2 ed. Porto Alegre: Nova Dimensão, 1988.

FUNARI, P. P. A. Arqueologia. São Paulo: Editora Ática, 1988.

GEERTZ, C. A interpretação das culturas. Rio de Janeiro: Ed. Zahar, 1978.

GUTIERREZ, R. As missões jesuíticas dos guaranis. [Bilíngüe]. Rio de Janeiro: Unesco, 1987.

HAUBERT, Maxime Indios e jesuítas no tempo das missões Círculo do Livro, Companhia das Letras, São Paulo. 1990

KERN, A. A. Missões: uma utopia política. Porto Alegre: Mercado Aberto, 1982.

KERN, A. A. O Sítio-escola Internacional do Pós-graduação em História do Instituto de Filosofia e Ciências Humanas da PUCRS e sua importância e significado Texto apresentado na Reunião da SAB, 1993. 
ORSER Jr., C. E. Introdução a arqueologia histórica. Belo Horizonte: Oficina de Livros, 1992.

POPESCU, O. EI sistema econòmico en las misiones jesuíticas. 2 ed. Barcelona: Ed. Ariel, 1967.

RAHMEIER, C. S.; CARLE, C. B. Relatório do Projeto de Levantamento, Salvamento e Monitoramento: Arqueologia e Valorização Patrimonial de pátio de residência em Santo Ângelo Custódio. Cruz Alta: UNICRUZ/CEPA-PUCRS, 2004.

REDMAN, C. L. Multistage Fieldword and Analitical Techniques. American Antiquity, v. 38, n. 1, 1973.

SEPP, A. Viagens as missões jesuíticas e trabalhos apostólicos. São Paulo: Biblioteca Histórica Brasileira, EdUSP, Livr. Martins Fontes, 1972.

SOUZA, J. O. C. Projeto Cultura Material Assentamento e Ambiente Natural no Sítio Missioneiro de São João Batista. In: Anais do IX Simpósio Nacional de estudos missioneiros - as missões depois das missões. 8 a 10 de out. de 1991, Unijuí Câmpus Santa Rosa, Santa Rosa. 1991. 